\title{
Organisational routines in the light of 'old' evolutionary economics: Bringing politics back into the study of organisational learning
}

\author{
EDWARD LORENZ*
}

\begin{abstract}
Research in organisational behaviour has largely focused on the cognitive features of organisational routines and learning to the neglect of their political determinants. This paper draws inspiration from J.R. Commons' theory of institutional change to develop a more integrated account giving due weight to the political dimension. The first section of the text develops the key analytical distinction Commons makes between habit and custom. Habit, much as the notion of routine, refers to repeated behaviour and to the individual learning processes that account for its emergence. Custom refers to the collective sanctions and pressures which channel such individual learning processes in socially acceptable directions. The paper shows how this distinction allows Commons to analyse the way repeated behaviour at the individual level is embedded in a wider group or social context. The second section of the text turns to Common's theory of dispute resolution. It is argued that his analysis contains the elements of a theory of organisational change, or of the processes which change routines, that involves a constant interplay between centralised intervention and the unplanned local emergence of practices and behaviours.
\end{abstract}

\section{Introduction}

Organisational theory, since the seminal work of March and Simon (1958), has viewed routines as fundamental building blocks of a theory of the firm in which the characteristics of internal decision making processes are important for understanding decision outcomes. Moreover, routines, with their properties of sub-optimality and inertia, have come to be seen as essential ingredients of a theory that can account for differences in how different firms go about accomplishing similar tasks and for strong elements of continuity in their behaviours ${ }^{1}$.

Following the publication of Nelson and Winter's An Evolutionary Theory of Economic Change (1982), it has become common to distinguish the 'cognitive' basis of routines from their basis in 'political' processes. Nelson and Winter, though, devoted a scant

\footnotetext{
* Centre d'études de l'emploi, Noisy-le-Grand, France. E-mail: Lorenz@alum.mit.edu

${ }^{1}$ See, for example, Dosi, Nelson and Winter (forthcoming, p. 19).

Keywords: Organisational routines, organisational learning, custom, habit.
} 
five pages to the political side of the matter in the section of their book titled 'routine as truce' (1982, pp. 107-112). While to my knowledge no one has made an explicit count, I do not believe anyone would contest the view that in subsequent research on organisational routines the emphasis has been on the cognitive dimension. Although recognition is frequently given to the importance of conflictual determinants, it is hard to identify a single publication focussing on this issue that has made a significant impact on subsequent research in the field ${ }^{2}$. One cannot but agree with the recent assessment of Massimo Egidi (in Cohen et al., 1995, p. 48) that gaining a better understanding of the links between the cognitive and the conflictual forces which give rise to the persistence of routines remains one of the important challenges facing organisational theory.

This paper draws on J.R. Commons' theory of institutional change to offer some suggestions for developing a more integrated account of routines and organisational learning, or the processes that change routines ${ }^{3}$. The programmatic advice offered here remains incomplete in the sense that the cognitive aspect of routines is examined from a partial angle, namely the relational and organisation-specific knowledge that individuals require in order to get the job done. I do not consider in any detail that other building block of routines, to wit modular or relatively context-independent know-how, such as that required for operating a lathe or performing standard equipment maintenance. Another way of stating this limitation is that the analysis in the paper captures better the idea of routine as 'organisational memory' than it does the idea of routine as 'skill' 4 .

In order to clear the ground and to establish the prima facie relevance of Commons' institutional analysis to the task at hand, I propose to start by situating his thinking relative to certain key issues under debate in current research on organisational routines. I will then proceed with a presentation of the basic elements of his evolutionary theory of institutional change. The concluding section of the paper suggests ways in which Commons' ideas can serve as inspiration for a more integrated account of routines and of organisational learning.

\section{J.R. Commons and the debate over routines}

The first problem issue I have in mind is that of rules vs. behaviours. The question is whether research should focus on routines understood as rules or representations, or rather on routines understood as behaviour, which may be an expression of such rules ${ }^{5}$ ? It is worthwhile emphasising that the issue at stake here is not whether man is a

\footnotetext{
${ }^{2}$ A possible exception to this claim is the recent working paper by Coriat and Dosi (1994) which develops the idea that routines serve a dual function, both as mechanisms for co-ordinating distributed knowledge and as mechanisms for internal governance.

3 This paper draws exclusively on Institutional Economics: Its Place in Political Economy (1934) which, as Rutherford (1990, p. xvii) has observed, is generally accepted as being the most complete statement of Commons' methodology. The Economics of Collective Action (1950) is a simplified version of Institutional Economics, while The Legal Foundations of Capitalism (1924) focuses more narrowly on the concept of reasonableness in court decisions and has little to say about managerial relations.

${ }^{4}$ For the distinction between the two building-block of routines, see Nelson and Winter (1982, pp. 100-103).

${ }^{5}$ For varying positions on this question, see Cohen et al. (1995, pp. 21-24).
} 
processor or manipulator of rules, in the sense of standard operating procedures, instruction manuals, and the like. This is undeniable, and the way man's use of such 'cognitive artefacts' can transform the properties of the computations undertaken in achieving a task constitutes an object of study in its own right ${ }^{6}$. Rather, the issues at stake here are: firstly, whether man's 'cognitive architecture' 7 should be conceived as being symbolic and rule-based; and secondly, whether his behaviour should be understood to be an outcome of the cognitive processes taking place within that architectural frame.

Different points of view regarding these issues can to some extent be understood in terms of the classic opposition in psychology between 'cognitivism' and 'behaviourism' ${ }^{8}$. Cognitivism, often associated with Newell and Simon's 'physical symbol system hypothesis', has been described by Dreyfus (1990, p. 2) as involving two basic hypothesis. The first is that, "our ability to deal with things intelligently is due to our capacity to think about them reasonably (including subconscious thinking)". The second is that, "our capacity to think about things reasonably amounts to a facility for internal automatic symbol manipulation". The upshot of these two premises is that all behaviour, including automatic skilful performance, can be explained as the result of rule-governed metal processes or executions of programs expressed in some symbolic language. From this perspective, a routine is just another term for an algorithm or a program, and advancing research on organisational behaviour and learning will necessarily depend on investigating how such algorithms emerge and evolve in collective problem-solving settings ${ }^{9}$.

Cognitivism, as is well known, developed as a reaction to behaviourism which itself developed in response to what was perceived as the excessively subjective, and hence unscientific, nature of introspectionism in psychology at the turn of the century. Hutchins (1995, p. 371) has described behaviourism as the view that internal cognitive structure is either non-existent or unimportant, and that the study of behaviour can be undertaken entirely in terms of an objective study of behaviour itself. Stated in this stark manner, I doubt that any of the major participants in the current debate on routines would describe themselves as behaviourists. Nonetheless, it is possible to find remarks suggesting a certain affinity to behaviourism, in the sense of casting doubt on the view that intelligent behaviour is necessarily due to rule-based metal processes ${ }^{10}$ :

\footnotetext{
${ }^{6}$ This is one of the central issues investigated by Hutchins (1995), for example.

${ }^{7}$ Following Newell et al. (1989), cognitive architecture can be defined as, "the fixed structure that provides the frame within which cognitive processes in the mind takes place". Moreover, the authors caution (p. 103) that the architecture, composed of memory, symbols, operations and interpretation, should not be confused with a representation of the external world. The architecture supports such a representation but does not itself provide it.

${ }^{8}$ For this insight, I am indebted to Bessy (1997).

${ }^{9}$ This stance is clearly articulated by Egidi in the Appendix to Cohen et al. (1995).

${ }^{10}$ Surprisingly little attention has been given in the organisational behaviour literature to current debates in cognitive science focusing not on the question of the importance or the existence of internal cognitive architecture, but rather on the question of whether this architecture should be conceived as being symbolic and rulebased. In particular, those of a connectionist persuasion have cast doubt on the universal applicability of Newell and Simon's physical symbol system hypotheses, particularly as an explanation of know-how as opposed to know-that. For a good introduction to these debates, see the 1993 special issue of Cognitive Science.
} 
"Indeed, I totally agree that the relation between the two levels [representation $v s$. expression], however defined, is a promising area of investigation. However, I would not go as far as drawing an analogy with the genotypical-phenotypical distinction in biology. First, I am not convinced that representations are equivalent to some genotypical level. I would find that at least equally plausible to think of actual action/behavioral patterns as the genotypes, which reproduce via apprenticeship and acculturation mechanisms within organizations, and imperfect imitation across organizations. Relatedly, it is not implausible to think of representations as sorts of imperfect and mostly ex-post rationalizations of what has been done, should be done, one wished ought to be done..." (Dosi as cited in Cohen et al., 1995, p. 24).

Where should Commons be situated relative to this debate? Clearly it would be wrong to classify Commons as a behaviourist. $\mathrm{He}$ is at some pains to distinguish his approach from the behaviourists who he describes as, "those who reject ideas altogether as merely subjective and unmeasurable, basing their psychology on the glands, muscles, nerves and blood currents, etc." (IE, p. 106) ${ }^{11}$. On the other hand, he is little concerned to investigate the framework within which thinking takes place. He repeatedly refers to the need for a "negotiational psychology" which takes as it subject matter "human being as citizens and members of going concerns" and not "human beings as natural objects of study"(IE, p. 156).

A central reason for this, I believe, has to do with the influence of Pragmatism, and in particular the ideas of Peirce, on Commons' understanding of the relation between thinking, beliefs and habits of action. Commons' position is clearly laid out in the section of Institutional Economics devoted to Pragmatism, where he claims to have adopted Peirce's methodology in his own work. Citing Peirce, the following points are made (IE, p. 152). First, the mind is an "active organiser of impressions" rather than a passive register of them as in Hume's empiricism. Second, the purpose of thought or metal activity is the "formation of belief". Third, belief has a number of characteristics, the most notable of which is the "establishment in our nature of a rule of action, or, say for short, a habit". The point is stressed by noting that, "whatever there is connected with a thought, but irrelevant to its purpose [i.e. producing beliefs and habits], is an accretion to it, but no part of it" (IE, p. 152).

Observe that this does not amount to saying that internal cognitive structure is nonexistent or unimportant. It does, however, allow Commons to set aside the problem of attribution, in the sense of producing the sorts of evidence that could support a particular hypothesis concerning the nature of this architecture. As far as the study of economic relations is concerned, Commons' opinion is that what counts about thinking is the sensible effects it produces, namely beliefs or assumptions and habits of action:

"Yet opinion and action cannot be separated in scientific investigations, for action is opinion-in-action and science measures the action while inferring the opinion. Habitual and customary assumptions are read into habitual and customary acts.

\footnotetext{
${ }^{11}$ The abbreviation IE refers throughout to the 1990 Transaction edition of J.R. Common's Institutional Economics: Its Place in the Political Economy.
} 
Here the process of investigation is similar to psychoanalysis, but, instead of an individualistic science which investigates nerves or dreams as an explanation of individual behaviour, social science investigates habitual and customary assumptions as an explanation of transactions"' (IE, p. 698).

Commons' way of dealing with the problem of the relation of mind to behaviour is unlikely to prove satisfactory to those convinced that serious progress in the behavioural sciences will depend on developing the experimental methods that will allow us to lay open the inner framework of cognition. On the other hand, Commons' vision of human agency in which behaviour is accounted for in terms of habit and routine rather than selfconscious deliberation and optimising choice is probably one that would receive wide acceptance by those who look to the notion of routine as providing a foundation for an alternative to the neo-classical theory of decision making.

The second problem issue I want to briefly tuch upon is that of automaticity and tacitness vs. deliberateness and self-awareness. The issue here is to what extent should automatic behaviour, which draws on implicit knowledge about which the individual has little self-awareness, be considered a defining feature of routines? The difficulty here is that if one allows routines to include deliberate choice and self-conscious problemsolving, then the concept arguably becomes all-encompassing. It becomes difficult to exclude rational choice, involving the application of particular rules and algorithms (e.g. linear programming methods, Bayes' rule, etc.) from falling under its rubric ${ }^{12}$. For this reason, many participants in the current debate would make tacitness and automaticity defining features of routines.

For Commons, as with Peirce, the beliefs which produce actions are mostly implicit or tacit. In the section of Institutional Economics titled 'Habitual Assumptions', he states that if we want to understand why individuals act in the way they do we need to examine, "the assumptions which they take for granted as so familiar they are not formulated in words" (IE, p. 597). As the following quote suggests, familiarity is the basis for the emergence of such implicit beliefs or assumptions which find their expression in automatic, routine behaviour:

"When a new worker goes into a factory or on a farm, or when a beginner starts in a profession or a business, everything may be novel and unexpected because not previously met in his experience. Gradually he learns the ways of doing things that are expected from him. They become familiar. He forgets that they were novel when he began. He is unable even to explain them to outsiders. They have become routine, taken for granted. His mind is no longer called upon to think about them. [...] We speak of such minds as institutionalized. But all minds are institutionalized by whatever habitual assumptions they have acquired and they take for granted, so that they pay no attention to them except when some limiting factor emerges and goes contrary to what they were habitually expecting', (IE, pp. 697-698).

\footnotetext{
12 This was pointed out to me by L. Marengo in private conversation.
} 
While belief is mostly implicit or taken for granted, as the reference to "limiting factor" suggests, there is a place in Commons' thinking for more self-conscious and deliberate choice. This issue is taken up in the section below following a presentation of the basic elements of Commons' institutional analysis.

\section{Habit and custom in Common's institutional economics}

While the relation between beliefs and action is at the core of Commons' analysis, investigating the fixed structure within which thinking takes place is not. While this limits the relevance of his work to some of the issues that are of concern in the contemporary literature on routines and organisational behaviour, it does present certain advantages. One cannot help but conclude that the emphasis on the cognitive foundations of organisational behaviour found in much of the contemporary literature inspired by the work of Simon (1947) and March and Simon (1958) has encouraged theorists to develop models of the firm by analogy with models of the mind ${ }^{13}$. One, possibly unintended, consequence of this has been a manifest tendency to reproduce in organisational analysis a characteristic feature of most mainstream cognitive science, namely to restrict the analysis to computation or symbol processing that occurs within the 'cognitive entity' - be it a mind or an organisation - and to neglect the importance of the entity's interactions with the external environment. This consequence is implicitly recognised by March and Simon, who observe in the introduction to the 1993 edition of Organizations that their approach, "may have resulted in understating the significance of the historical and social context of action" (p. 16). Commons' work, I would argue, provides a useful framework for resituating organisational behaviour in a wider institutional context in a way that is not incompatible with attaching importance to mind and cognitive capabilities ${ }^{14}$.

Commons basic unit of institutional analysis is the transaction. By this he does not mean the exchange of commodities in the physical sense. Rather he has in mind the alienation and acquisition of rights which bear on individuals' future use and ownership of things:

"If I look at or participate with people actually engaged in transactions [...] I find futurity always there, not in production or consumption, but in the persuasions or coercions of bargaining transactions, the commands and obedience of managerial transactions, and the arguments and pleadings of rationing transactions, which

\footnotetext{
${ }^{13}$ For a variety of evidence in support of this claim, see the article by Mangolte in this volume.

${ }^{14}$ One consequence of the tendency to downplay the importance of the external environment, as work on 'everyday cognition' by cognitive anthropologists such as Hutchins (1995) as shown, is a failure to understand how the cognitive properties of groups may differ from those of the individuals who makes them up, due to the way mediating structure such as equipment, tools and written instructions transform the nature of the computations required of individuals in order to accomplish a collective task. Commons' approach, I would contend, is entirely compatible with the programmatic advice of Hutchins (1995, p. 135), that without making any premature commitment to a particular model of internal cognitive architecture, we can advance our understanding of human cognition by examining how the structure of tasks and the nature of mediating artefacts establish computational constraints that must be satisfied by the system as a whole.
} 
will ultimately determine production and consumption. In these negotiations and decisions, which are the essence of institutional economics, it is always future production and future consumption that are at stake, because the negotiation determines the legal control which must proceed physical control', (IE, p. 7).

By bargaining transactions Commons is referring to the transfer of ownership of wealth by voluntary agreement between legal equals. Managerial and rationing transactions, on the other hand, concern relations between superiors and subordinates. Managerial transactions are those whose purpose is the creation of wealth by establishing rights of command which inferiors must obey, such as the relations of "foreman to worker" or "manager to managed". Rationing transactions, on the other hand, concern the rights of a collective superior (e.g. board of directors, arbitration tribunal, taxing authority, etc.) who "prorates among inferiors the burdens and benefits of the concern" (IE, pp. 59-60).

Common's definition of transactions in terms of the future ownership of things is concordant with his oft repeated view, "that man lives in the future but acts in the present". Moreover, this "future is wholly uncertain except as based on reliable inferences drawn from experiences in the past" (IE, pp. 57-58). Commons emphasises the behavioural sources of this uncertainty or insecurity, while not ignoring possible environmental sources. Behavioural uncertainty follows from the fact that while all economic relations contain an element of mutual dependence, since one's ability to "live and prosper" depends on what others do, they also invariably contain an element of conflict, which stems from the fundamental fact of "scarcity" and from the transacting parties efforts, "to get as much and to give as little as possible" (IE, p. 118). Commons summarises his view of the matter as follows:

"For insecurity is not so much the accidents resulting from unintentional forces of nature as it is the insecurity of intentions, negligence, and caprice on the part of those having superior physical or bargaining power. The former insecurity can be, and has been, largely avoided by the technological improvements that bring nature's forces under control, but the latter insecurity can be avoided only by the stabilization of the wills of those having authority", (IE, p. 705).

On Commons' account, the transactions which make up "going concerns" such as firms, unions, the courts, political parties and the state simply will not occur without some reduction of uncertainty. This "security of expectations" is provided for by various customs or working rules. These behaviour regularities are not given by nature, however, but rather are historically contingent human creations which are in a constant state of evolution. At any point in time, as Commons states in his discussion of Peirce's methodology, they are rooted in the beliefs or assumptions individuals hold concerning the likely behaviour of others in recurrent situations (IE, pp. 40-52; 144-157) ${ }^{15}$.

Security of expectations, that "ultimate principle without which man cannot live in society" (IE, p. 705), is not something that can be explained simply by reference to indi-

\footnotetext{
15 There is little appreciation of the fact that in arguing that rules and customs provide security of expectation Commons is clearly anticipating D. North's (1991) defintion of institutions as humanly devised rules that serve to reduce uncertainty in society.
} 
vidual processes of habituation based on repetition. Rather, it also depends on various collective sanctions and compulsions. In developing his view of the social basis of behavioural regularities, Commons draws a key distinction between habit and custom. Habit refers to repeated behaviour at the individual level and to the psychological mechanisms that generate it. (IE, pp. 155; 701-702; 740). Custom, on the other hand, refers to the conformity of individual behaviour to certain widely-shared rules of behaviour. As Commons puts it, "it [custom] is repetition by the continuing group of changing persons". The basis for custom is education, which Commons describes as the "social process of acquiring habits through life-long repetition of dealings with others and the necessity of conformity enforced through collective action" (IE, p. 155):

"Individuals do not start de novo - they start as babies, then continue as infants, then enter occupations, and are learning to fit themselves to custom. If their habits do not fit, then they cannot make a living of their own efforts, and are recipients of charity, or beneficiaries of the laws of inheritance"' (IE, pp. 701-702).

The point he is making here, one that is implicit in the above quote about the habituation of a worker to the ways of a particular factory, is that individuals begin the process of acquiring customs, or of learning how to fit in, in a relatively self-conscious manner. To the extent that they hope to be accepted as members of "going concerns", they will more or less self-consciously seek to understand and to adapt their behaviour to the organisation's "working rules". The consequence of a failure to conform is exclusion from the transactions upon which their livelihood depends. If the organisation's rules are stable, then they will repeat the transactions, and, with sufficient repetition, the assumptions underlying the behavioural regularities will become implicit until the "mind is no longer called upon to think about them" (IE, p. 698).

In differentiating habit from custom, Commons introduces a key analytical distinction that is missing from contemporary studies of organisational behaviour based on the concept of routine. While not denying the importance of individual learning processes, this distinction allows Commons to develop an analysis of behaviour which is embedded in a wider social or group context. On his account, the socially compulsory nature of custom is what makes the analysis truly "institutional economics" (IE, pp. 69-74).

Commons refines his analysis by arguing that customs are experienced by individuals as being more or less compulsory depending the kind of sanction that applies, the degree of precision of the behavioural standard and how widely diffused it is (IE, pp. 708-709). Three types of sanctions are distinguished by Commons: moral, economic and physical. By moral sanction he is referring to the compulsion of similarity of opinion. By economic sanction he is referring to the way failure to conform imposes pecuniary loss by threatening to exclude the individual from participating in productive activities. As examples he refers to the fact that the businessman who refuses the custom of purchasing commodities and paying debts by means of cheques on solvent banks will not be able to get into business. Similarly, the worker who refuses to come to work when others come will not get employment. In such cases, what serves to enforce the custom is all individuals acting alike. Physical sanctions denote the use of violence to enforce conformity. On his account, a defining characteristic of the modern state is its progressive establishment of a monopoly on the use of such violence (IE, pp. 706-708). 
Customs can be distinguished according to their precision and degree of diffusion. A "practice", which might apply to an individual firm or association, is relatively imprecise and thus the least compulsory. A "usage", which is a more "widely imitated" practice is both more precise and has greater force. A "precedent", which is the most precise and therefore most compulsory, has "the peculiar binding force that it is a standard used in the decision of disputes and regulation of conduct by a higher authority having power of control" (IE, p. 709) ${ }^{16}$.

It is evident from the above discussion that Commons' notion of custom refers to behavioural in a wider range of contexts than does the notion of routine in the contemporary literature on organisational behaviour. Custom is used to refer both to repeated behaviour within individual organisations and to society's general rules. Commons' tendency to use such terms as "working rules" and "going concern" to refer to behaviour at either of these different levels is a source of confusion in his work and has been the subject of criticism, notably by Vanberg (1989). However, as the contrast he draws between practices, usages and precedents makes clear, Commons is concerned to distinguish between the levels in terms of how compulsory and how generally applied practices are.

Observe that at the level of the individual organisation Commons' notion of custom would appear to cover the same phenomena as the notion of routine, namely behaviour that is repeated. Moreover, in Commons' view, such behaviour displays the characteristics of automaticity and tacitness that are often taken to be defining attributes of routines in the contemporary literature. Commons' distinction between habit and custom, however, allows him to analyse something that is downplayed or ignored in the contemporary literature, namely the wider social or group context within which such repeated behaviour is embedded. The key idea, of course, is that collective pressures to conform channel individual learning processes in socially acceptable directions.

Viewed from the perspective of a single enterprise, behaviour may to some extent be accounted for on the basis of society's general customs or those which have high "publicity" to use Commons' term (IE, p. 709). Organisational behaviour is not determined by societal rules, however, since at the local level relatively idiosyncratic practices of low "publicity" are constantly emerging. The challenge in analysing behaviour in any particular instance is to correctly judge the balance of levels and types of sanctioning mechanism which are in operation.

\section{Limiting vs. complementary factors}

Given that the beliefs or assumptions that are read into customary behaviour are mostly implicit, one might well ask: Does Commons carve out a place for self-aware and deliberate choice in his institutional analysis? Self-awareness and deliberateness do find their place, and not only in the relative mundane sense that the initial stage of acquiring habits or customs depends on more or less self-conscious learning processes. One other way in which deliberate choice enters the picture is in Commons' discussion of the management

\footnotetext{
${ }^{16}$ These distinctions are returned to in the following section focusing on 'organisational learning'.
} 
of the "limiting" factors or critical physical resources upon whose sagacious use efficient outcomes depend:

"The limiting factor is the one whose control, in the right form, at the right place and time, will set the complementary factors at work to bring about the results intended. A very little potash, if that is the limiting factor, will multiply the grain yield from five to twenty bushels per acre. The sagacious mechanic is the one who busies himself with control of the limiting factor, knowing that the complementary factors will work out the results intended'' (IE, pp. 628-629).

Commons also considers the control of the limiting factors from the relational angle of man's efforts to deal with the unexpected or unusual in transactions. In considering the matter from this point of view, he identifies strategic or limiting factors with those individuals whose behaviour displays the qualities of being both uncertain and potentially critical for the smooth functioning of the "going concern".

"For the individual who would obtain advantages for self or others, the limiting factors are the particular behavior of self or others, at the time and place, upon which depends the complementary behavior of others. [...] In a manufacturing concern the limiting factor may be the mechanic, the foreman, the superintendent, even the scrub-woman, upon whose control, by means of managerial transactions of command and obedience, the totality of transactions depends. The result of this control is a "going plant" as a whole with its measurable efficiency" (IE, pp. 643644).

In other words, this latter case corresponds to a situation where one cannot take for granted the relations of command and obedience that tie superiors to subordinates in an organisation. Correspondingly, the transacting parties engage in more self-aware decision-making processes, possibly involving negotiation and compromise.

While the identification and control of the "limiting" or "strategic" factors depends on a capacity for reflection and deliberate choice, I would argue that Commons has in mind here a behavioural model which falls short of rational choice with its assumption of a capacity to compare the utility of all possible outcomes associated with crossing a set of possible actions with a complete list of possible states of the world. Rather, this "strange but familiar ability to act upon a single factor, out of hundreds and thousands of complex factors, in such a way that other factors shall, of their own inherent forces, bring about results intended" (IE, p. 89), would seem to have more to do with the notion of expertise and the expert's ability, based on experience and intuition, to narrow down the relevant range of options to a few that are the object of his conscious deliberation:

"This control [of the limiting factors] has one name, Timeliness. Timeliness is, indeed, learned by experience, and is part of that feeling of fitness which cannot be imparted by mere intellect. It furnishes the difference between Art and Science, between the abstract concepts of Willingness and the Concrete Will in action at a particular time, place and environment' (IE, p. 647).

Evidently, in terms of models of behaviour, the basic contrast set up by Commons is not, as in March and Simon (1958), between rational choice and boundedly rational choice in the form of 'satisficing' or otherwise. Rather, the distinction he highlights is between highly automatic behaviour grounded in beliefs that are implicit, and the 
decision-making of the expert who, guided by long experience, manages with little conscious effort to restrict his problem-solving energy to the strategic factors:

"It [controlling the strategic factors) is undoubtedly the greatest of all human gifts for men of action, which we name Timeliness, and is the outstanding gift of the greatest warriors, the greatest statesmen, and the greatest businessmen, bringing under their control a nation of flutterbudgets", (IE, p. 588).

While the basic contrast which Commons sets up is not identical to that drawn by March and Simon (1958), nonetheless, in pointing to man's limited capacity for rational decision-making and to the importance of focusing on a few factors at a time, he is clearly anticipating one of the foundation concepts of their approach to the study of organisations ${ }^{17}$.

\section{Organisational learning}

How should we understand organisational learning, defined as the processes that change rules and practices? The question is often posed in terms of a choice between two opposing models. Either change is conceived to be the result of deliberate planning on the part of some centralised authority with a model of the system as a whole, or it is understood to be the result of the unplanned interaction of local elements of the system that are adapting to changes in the behaviour of the other parts. While support for both views can be found in the literature on routines and organisational learning, I believe it would be fair to say that most participants in the debate would leave a large place for local adaptation and the spontaneous emergence of order. The following quote, taken from Dosi, Nelson and Winter (forthcoming) sums up a view that I believe enjoys wide currency:

“[...] organisational learning produces the coordinated performances of organisational capabilities without the aid of a recipe -alternatively without the aid of a comprehensive plan, optimized or not. [...] As learning proceeds, innumerable procedural details are settled by individual participants, with or without conscious awareness or consideration. [...] Tentative choices that are actually incompatible or substantially subversive of the overall performance get rooted out in the course of learning - not in response to the imperative "follow the recipe" but in response to "try something different!" Choices compatible with the overall performance are allowed to stabilize and become habitual, without either the choices or the habits necessarily being recognized as such along the way" (Dosi et al., forthcoming, p. 18).

How should Commons be positioned relative to these two opposing views? Given his view that the assumptions that are read into habits of action are for the most part implicit, it is perhaps surprising that he is often identified as supporting a 'planning' or 'design' view of how institutional rules are established and change. Two likely reasons for this can be raised. Firstly, as Lawson (1996, pp. 971-977) has admirably shown, this interpretation

\footnotetext{
${ }^{17}$ Indeed, March and Simon (1958, p. 191) give brief recognition to the originality of Common's thinking on this issue.
} 
of Commons' work can probably be attributed to a misunderstanding of the role of centralised authority in his work. The central authority, or "sovereign", acts not as a designer of rules and practices, but rather as a selector, who weeds out the 'bad' from the 'good'. The rules and precedents that are selected in turn give rise to new local practices which, in a manner comparable to that described in the above quote by Dosi et al., are allowed to stabilise and become habitual. The end result is a view of organisational change involving a constant interplay between centralised intervention and local adaptation.

A second explanation for the fact that many readers have identified Commons with a "design" interpretation of institutions may simply be that he gives little attention to the mechanisms explaining how new practices are introduced at the local level. The basic argument he makes concerns the way changing context conditions generate inevitable variability in existing practices:

"For custom is the mere repetition, duplication, and variability of practices and transactions. No repetition is exactly the same as its predecessor, and no duplication is exactly the same as its contemporary. Hence, there is always a variability of customs in successive times and at the same time. These variations in the course of history introduce new customs as variables, or as alternatives, of proceeding or contemporary customs...' (IE, p. 45).

However, he also refers to the way groups may consciously set out to change existing customs that they find go contrary to their interests (IE, p. 701). This suggests that Commons recognises a capacity for explicit design at the local level of the "going concern", even if this capacity is not a characteristic of those in positions of centralised authority ${ }^{18}$.

Regardless of how they come about, two defining characteristics of local practices of "limited publicity" are their lack of precision and their lack of compulsion. By lack of precision, Commons means that there exists ambiguity regarding the rights, duties and obligations of individuals involved in transactions. Thus, in the case of managerial transactions, local practices may be unclear regarding the range of tasks or duties that a superior can command of a subordinate, or they may be vague regarding who has a right of command. The factors accounting for this lack of precision are permissive in the sense that, absent a dispute, individuals face little pressure to make explicit their assumptions regarding rights of control over individuals.

The explanation for the relative lack of compulsion of local practices would appear to be much the same as that found in the contemporary analysis of convention equilibria (Sugden, 1986). Commons' reasoning is that absent some critical mass of imitators, the pressure to conform to a practice is necessarily weak:

"The practices of any individual, or firm or association may be variable and indifferent to others because not sufficiently imitated to induce general imitation, as when one person practices economy and the other practices extravagance. But a

\footnotetext{
${ }^{18}$ One might suppose, as Rutherford (1990, p. xxi) has suggested, that in coping with unexpected factors in their "strategic transactions" leaders and managers are led to design and implement new practices. To my knowledge, though, the connection between "strategic transactions" and the self conscious establishment of new practices is never explicitly made by Commons.
} 
usage becomes sufficiently imitated, so that, like language or bank checks, its use is practically compulsory on all who participate in transactions", (IE, p. 709).

Practices may give rise to usages of greater "publicity" through spontaneous processes of imitation. In contrast, relatively precise and compulsory precedents are established through more formal and deliberate processes of dispute resolution. On Common's account, the lack of precision of local practices constantly gives rise to disputes. Lack of precision is typically associated with a degree of incompatibility between the implicit assumptions held by the transacting parties over rights of command. Consequently this imprecision tends to bring to the fore the conflicts of interest which are latent in all transactions. If conflicts of interest break out into open disputes, upper level authority will intervene to solve the dispute by selecting the "good" practices and eliminating the "bad", thus establishing a precedent. This process, whereby dispute resolution leads to certain practices becoming more precise and binding on individuals, is what Commons means by the "common law method of making law":

"Hence, when we speak of the common law we mean not the technical common law of the legal profession, but the Common Law Method of Making Law by Deciding Disputes. The method is not confined to courts of law. It is the method of commercial arbitration, where the sanctions are not those of sovereignty. It is the method of making law in the family, the church, the labor union, the business concern. It is the method of precedent, choice of customs, unwritten law, and assumptions. Custom becomes common law by the common-law method of deciding disputes, thereby sanctioning what are habitually to be good customs in the act of condemning or not enforcing what are deemed to be bad or obsolete customs"' (IE, p. 707).

Precedents, once established, give rise to new local practices by the processes referred to above. The upshot of this line of reasoning is a cyclical conception of the processes which change rules, involving a constant interplay between informality and formality:

"They begin as optional practices with individuals, then become customs when individuals are compelled by customers and competitors to conform; then become precedents when disputes are decided; then statutes when formally declared by executive or legislative authority; then customs again when statutes are construed in particular disputes; and all along there are the changing, yet habitual assumptions when applied to particular transactions and disputes. They move along together', (p. 706).

Observe that this constant interplay between the centralised intervention of the "sovereign" and locally given practices also involves a constant interplay between the tacit and self-aware levels of consciousness ${ }^{19}$. This follows from the fact that as disputes are decided individuals are pressed to make precise their interests by articulating their

\footnotetext{
${ }^{19}$ For this point, I am indebted to C. Lawson who first raised it to me in private conversation. The basic idea of an interaction between the tacit and explicit levels is stated in Lawson (1996, p. 976-77).
} 
implicit assumptions concerning acceptable relations of command and obedience:

"Not until practices or usages are converted into precedents by the decision of disputes, do they become precise enough to be analysed logically with regard to the direction of control over individuals"' (IE, p. 710).

The end result of this interactive process is the wider diffusion of practices, as the good ones, which have been picked up by those in positions authority, serve as precedents for the resolution of disputes in comparable circumstances, both within and outside the particular going concern. Commons summed up this complex dynamic of selection and diffusion under the notion of "artificial selection" (Lawson, 1996, pp. 973-974; Rutherford, 1994, p. 109).

\section{Conclusion: Bringing politics back in}

Organisational research within the tradition of March and Simon (1958) has tended to focus on internal processes of decision-making and to conceive these in terms of the computational metaphor of problem-solving routines and heuristic search. Not only has this led researchers to neglect the political dimension of internal decision-making, but also it has discouraged them from examining the way the organisation's interactions with the external environment may shape its internal behaviour.

Cohen et al. (1995, p. 33) have recently come up with the relatively non-constraining definition of a routine as an organisation's learned capability for repeated performance in some context in response to selective pressures. Using this defintion as a point of departure, I propose to draw on Commons' institutional analysis in order to make some modest suggestions for rectifying the balance, by giving the neglected political and contextual dimensions of routines their due weight in the analysis. In so doing, I leave Commons' language and the detailed citations of his work behind, and rather couch the discussion in the idiom of the contemporary literature on organisational behaviour.

The starting point for this Commons-inspired account of routines is recognition that the organisational members, upon whose cooperation the organisation's capability for repeated task performance depends, are in recurring relationships that combine mutual dependency and conflict. Conflicts of interest in turn mean that members are always looking towards an uncertain future, since each party to the relationship will have an interest in modifying the arrangements in ways that will favour his interests, possibly at the expense of the interests of others. In such circumstances, sustained cooperation depends on establishing routines which are the expressions of relatively stable assumptions or beliefs concerning how self and others will behave in recurrent situations. In the absence of such beliefs or representations, production simply won't take place.

These beliefs, and the routines which are their expression, are learned through repetition. Over time they take on the distinctive properties of tacitness and automaticity. In terms of individual psychological mechanisms, these properties, and the local stability of routines they would seem to imply, could be linked to the reduction of cognitive load ${ }^{20}$

\footnotetext{
${ }^{20}$ See the discussion in Cohen et al. (1995, pp. 21-22).
} 
(Cohen et al., 1995, pp. 21-22), an idea that has much in common with Commons' view that habit frees up intellectual resources for dealing with the "limiting" or "strategic" factors in transactions (IE, p. 698). However, the critical point for this discussion is that, absent some disturbance, individuals will display a natural tendency to stick with particular behavioural patterns.

Routines are not randomly distributed within and across organisations. Sanctions of varying degrees of force channel individual learning processes in directions that make certain action sequences more likely than others. These sanctions or selective pressures may be local and specific to an individual work team or plants. Or, they may be of higher generality, generating pressures for the reproduction of particular routines across the production sites of a multi-plant firm or even across firms within a sector or nation. This variable notion of selective pressures or sanctions, then, avoids any simple reduction of organisational behaviour to external institutional conditions and provides a framework that allows to capture the interrelations between the local and higher levels.

Overt conflicts or disputes act to upset routine expectations. The meaning of an overt conflict is that there exists some lack of compatibility in the tacit beliefs of those involved in a collective task. Thus cooperation fails, and in the ensuing discussions and negotiations leading up to the resolution of the dispute the parties involved are pushed to examine their implicitly held assumptions concerning how production relations should be structured. In this process, they make their relational knowledge more precise and explicit and transform it into a form suitable for codification in formal and more authoritative rules and operating procedures. Moreover, because of their greater precision and authority, these formal rules and procedures often serve as benchmarks for the resolution of disputes in comparable circumstances. In this way certain practices are selected and diffused more generally within the organisation or even across organisations within a sector or nation. The end result is a conception of organisational learning in which conflict and its resolution are at the heart of the processes that change and diffuse routines.

By way of conclusion, it is appropriate to return to the limitations of the analysis that were alluded to in my introductory remarks to this paper. This account remains at best a starting point for developing an integrated approach to the study of routines and their change, since in terms of cognition the focus has been exclusively on what individuals need to know about their relations to others in order to accomplish what they do. Observe that in this account of routine performance, relational and organisation-specific knowledge is inherently political, in the sense that it incorporates knowledge about interests and the structure of decision-making authority. Correspondingly, it would be fruitless to neglect one or the other of these dimensions in any real-life study of routines and the processes that change them.

The approach sketched here remains a partial one, though, since it sets aside that other basic building block of routines, namely relatively modular skills such as knowing how to operate a standard lathe or knowing how to detect and correct quality faults in component production. Relative to the programmatic advice offered here, an appealing strategy for integrating this component of routines into the analysis would be to follow the advice of students of 'socially situated cognition', such as Hutchins (1994), Lave (1988) and Rogoff (1990), and examine the interplay between context and cognitive skills. These researchers have intentionally abandoned the controlled setting of the laboratory for field 
research designed to investigate man's exercise of "everyday cognitive skills", such as those mobilised by ship's navigators, by machine operators or by instructors in classroom settings. One of the key lessons they have drawn from their work is that context constrains and aides individuals in undertaking the computations required for collective task performance. By context they mean not only tools, plant layout, and the use of socially devised rules of thumb and the like, but also the nature of the relationships individuals enter into with one another when engaged on collective tasks.

The emphasis on contextual determinants in studies of socially situated cognition is fully compatible with Commons' focus on the institutional forces accounting for habitual or routine behaviour. Commons, of course, does not concern himself especially with how contextual factors condition the exercise of everyday cognitive capabilities. His focus is decidedly on the relationships themselves and how rights of ownership and use are acquired and alienated. But the onus I have set myself in this paper is not to show that Commons' work captures fully what is intended by the 'cognitive' dimension in the analysis of routines and the processes that change them. Rather, the burden of my discussion has been to show that Commons' approach to the study of "habitual assumptions" and "custom" does not shut the door on such an extended enquiry. In is in this sense that I would contend that his institutional methodology provides a promising starting point for the development of a truly integrated approach to the study of routines and organisational learning that does justice to both their political and cognitive dimensions.

Acknowledgments. I am especially indebted to Clive Lawson who first suggested that I write a paper addressing the relevance of J.R. Commons' institutional economics to contemporary debates on organisational learning. I draw substantially on his published work in the fourth section of this paper. I have also benefited from numerous discussions with Christian Bessy on the relation of Herbert Simon's work to contemporary work focussing on the cognitive foundations of organisational behaviour.

\section{References}

Bessy C. (1997) L'Hypothèse de connaissance tacite dans la théorie évolutionniste de la firme, unpublished working paper. Centre d'études de l'emploi, Noisy-le-Grand.

Coriat B., Dosi G. (1994) Learning How to Govern and Learning How to Solve Problems: On the Co-evolution of Competences, Conflicts and Organizational Routines, unpublished working paper, IASA, Laxenburg, Austria.

Cohen M., Burkhart R., Dosi G., Eidi M., Marengo L., Warglien M., Winter S. (1995) Routines and Other Recurring Action Patterns of Organizations: Contemporary Research Issues, working paper, Santa Fe Institute, Santa Fe.

Commons J.R. ([1934], 1990) Institutional Economics: Its Place in the Political Economy, Transaction Publishers, New Brunswick.

Dosi G., Nelson R.,Winter S. (forthcoming) The Nature and Dynamics of Organizational Capabilities, Oxford University Press, Oxford.

Dreyfus H.L. (1990) Socratic and Platonic Sources of Cognitivism. In: Smith J.C. (Ed.), Historical Foundations of Cognitive Science, Kluwer Academic Press, Norwell, MA. 
Hutchins E. (1995) Cognition in the Wild, MIT Press, Cambridge, MA.

Lave J. (1988) Cognition in Practice, Cambridge University Press, Cambridge.

Lawson C. (1996) Holism and Collectivism in the Work of J. R. Commons, Journal of Economic Issues XXX, pp. 967-984.

March J., Simon H. ([1958], 1993) Organizations, Blackwell, Cambridge, MA.

Nelson R., Winter S., (1982) An Evolutionary Theory of Economic Change, Harvard University Press, Cambridge, MA.

Newell A., Rosenbloom P.S., Laird J.E. (1989) Symbolic Architectures for Cognition. In Posner M.I. (Ed.), Foundations of Cognitive Science, MIT Press, Cambridge, MA.

North D (1991) Institutions, Institutional Change and Economic Performance, Cambridge University Press, Cambridge.

Rogoff B. (1990) Apprenticeship in Thinking: Cognitive development in Social Context, Oxford University press, Oxford.

Rutherford M. (1990) Introduction to J.R. Commons, Institutional Economics, Transaction Publishers, New Brunswick.

Rutherford M. (1994) Institutions in Economics: The Old and the New Institutionalism, Cambridge University Press, Cambridge.

Simon H.A. (1947) Administrative Behaviour, Macmillan, New York.

Sugden R. (1986) The Economics of Rights, Co-operation and Welfare, Blackwell Publishers, Oxford.

Vanberg V. (1989) Carl Menger's Evolutionary and John R. Commons' Collective Action Approach to Institutions: A Comparison, Review of Political Economy 1, pp. 334-360.

to access this journal online:

www.edpsciences.org 
